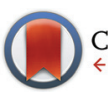

CrossMark \& click for updates

Cite this: Dalton Trans., 2014, 43 17101 DOI: $10.1039 / \mathrm{c} 4 \mathrm{dt} 02630 \mathrm{f}$ www.rsc.org/dalton

\section{Tetrametallic lanthanide(III) phosphonate cages: synthetic, structural and magnetic studies $\uparrow$}

\author{
Karzan H. Zangana, Eufemio Moreno Pineda and Richard E. P. Winpenny*
}

Received 28th August 2014 Accepted 25th September 2014

\begin{abstract}
The synthesis, structures and magnetic properties of a family of lanthanide complexes containing phosphonate ligands are reported. Reaction of hydrated lanthanide nitrate and tbutylphosphonic acid under reflux conditions in iso-butanol, in the presence of pivalic acid as a co-ligand produced five new lanthanide complexes; pyridine (py) was present as a base. The compounds formed are tetrametallic, with the general formula $[\mathrm{pyH}]_{4}\left[\mathrm{Ln}_{4}\left(\mu_{3}-\mathrm{OH}\right)\left(\mathrm{O}_{3} \mathrm{P}^{t} \mathrm{Bu}\right)_{3}\left(\mathrm{HO}_{3} \mathrm{P}^{t} \mathrm{Bu}\right)\left(\mathrm{O}_{2} \mathrm{C}^{t} \mathrm{Bu}\right)_{2}\left(\mathrm{NO}_{3}\right)_{6}\right]$ where $\mathrm{Ln}=\mathrm{Gd}{ }^{\prime \prime \prime}, 1$; $\mathrm{Tb}^{\prime \prime \prime}, 2$; Dy"', 3; $\mathrm{HO}^{\prime \prime \prime}, \mathbf{4}$ and $\mathrm{Er}^{\prime \prime \prime}, \mathbf{5}$. The metal sites within the complexes lie on the vertices of a triangle-based pyramid, with phosphonate ligands on the triangular faces linking the apical Ln site to the Ln sites in the base. Each lanthanide(III) site is eight-coordinate. Magnetic studies of the compounds show a decline in the product $\chi_{M} T$ with $T$; modelling the behaviour of 1 shows anti-ferromagnetic exchange between $\mathrm{Gd}^{\text {III }}$ centres within the triangle with a negligible interaction to the fourth $\mathrm{Gd}^{\prime \prime \prime}$ centre at the apex of the trigonal pyramid.
\end{abstract}

\section{Introduction}

During the past two decades, the synthesis and characterisation of metal phosphonate cages has been an attractive field of synthetic chemistry and molecular magnetism for their aesthetically pleasant structures with interesting magnetic properties, ${ }^{1}$ including some examples of single molecule magnets (SMMs). ${ }^{2}$ Other metal phosphonate cages have been studied as possible magnetic refrigerants. ${ }^{3}$ Phosphonate moieties are interesting functional groups for the construction of molecular cages, as the three tetrahedral oxygen atoms mimic well the zeolite building blocks, providing suitable anchoring sites for a large variety of metal ion centres (including both transition metals and lanthanides). ${ }^{4}$ It is also possible to influence the reactivity of compounds using the steric bulk of the phosphonate ligands. $^{5}$

Many research groups, notably those of Clearfield and Zubieta have used phosphonate ligands to synthesise a large number of metal phosphonates that possess mainly extended structures 1D-coordination polymer, 2D-layered structured and 3D-pillared structures. ${ }^{6}$ As a result of these studies a wide range of $3 \mathrm{~d}$-phosphonate and $3 \mathrm{~d}-4 \mathrm{f}$ phosphonate cages have

School of Chemistry and Photon Science Institute, The University of Manchester, Oxford Road, Manchester M13 9PL, UK.

E-mail: richard.winpenny@manchester.ac.uk

$\dagger$ Electronic supplementary information (ESI) available: Cif files, further synthetic details, structural and magnetic plots. CCDC 1021470-1021474. For ESI and crystallographic data in CIF or other electronic format see DOI: 10.1039/c4dt02630f been synthesised. ${ }^{7}$ In contrast to transition metal phosphonates, reported molecular assemblies of purely $4 \mathrm{f}$-phosphonates are rare. The first reported lanthanide phosphonates where prepared in 1990 by Mallouk and coworkers; ${ }^{7}$ cerium and lanthanum phenylphosphonates with composition $\left[\operatorname{Ln}\left(\mathrm{O}_{3} \mathrm{PC}_{6} \mathrm{H}_{5}\right)\left(\mathrm{HO}_{3} \mathrm{PC}_{6} \mathrm{H}_{5}\right)\right]$ and a series of alkylphosphonates such as $\left[\mathrm{Ln}\left(\mathrm{O}_{3} \mathrm{PMe}\right)\left(\mathrm{HO}_{3} \mathrm{PMe}\right)\right]$ were reported. Recently, we have been synthesising molecular cages of lanthanide metal ions with phosphonate ligands with the aim of preparing new cages, optimistically with interesting physical properties. ${ }^{8}$

Lanthanide phosphonate complexes normally have low solubility and poor crystallinity in water and organic solvents, hence it is generally difficult to obtain single crystals suitable for X-ray structural analysis. ${ }^{9}$ One of the major reasons for this is that the multisite coordination ability of the phosphonate ligands leads to the formation of insoluble compounds. We and others have proved that synthetically, this problem can be overcome for 3d-metal ions by different strategies, the first example arises from an initial report by Chandrasekhar and Kingsley ${ }^{10}$ where a second ligand is added alongside the phosphonate. The co-ligand occupies certain number of coordination sites on the metal ion as a result of which the number of coordination sites that are accessible for the phosphonate ligands decrease and soluble products can be isolated in the form of single crystals. This methodology has been used with a co-ligand to synthesise molecular cages containing manganese,${ }^{11}$ iron, ${ }^{12}$ cobalt, ${ }^{13}$ nickel, ${ }^{14}$ copper, ${ }^{15}$ vanadium. ${ }^{16}$ A second method for introducing a phosphonate or ligand without causing an immediate precipitate is to react the ligand with a preformed metal carboxylate cage, which was originally 
reported for iron and manganese and has since been extended by our group and others. ${ }^{17,18}$

In this work, we extend the co-ligand approach to $4 \mathrm{f}$-ions, reacting simple lanthanide salts $\mathrm{Ln}^{\mathrm{III}}\left(\mathrm{NO}_{3}\right)_{3} \cdot n \mathrm{H}_{2} \mathrm{O}\left(\mathrm{Ln}^{\mathrm{III}}=\mathrm{Gd}\right.$, $\mathrm{Tb}$, Dy, Ho and Er) with $t$-butylphosphonic acid $\left(\mathrm{H}_{2} \mathrm{O}_{3} \mathrm{P}^{t} \mathrm{Bu}\right)$ in the presence of pivalic acid $\left(\mathrm{HO}_{2} \mathrm{C}^{t} \mathrm{Bu}\right)$ as a co-ligand, giving tetrametallic lanthanide phosphonate cages.

\section{Experimental section}

\section{Starting material}

All reagents, metal salts, solvents and ligands were used as purchased without any further purification. Analytical data were obtained by the microanalytical service of the University of Manchester, the data and yields are given in Table 1.

\section{Synthetic method}

Pivalic acid (0.8 g, $7.83 \mathrm{mmol}), \mathrm{Gd}\left(\mathrm{NO}_{3}\right)_{3} \cdot 6 \mathrm{H}_{2} \mathrm{O}(0.55 \mathrm{mmol})$, $t$-butyl phosphonic acid $(0.07 \mathrm{~g}, 0.50 \mathrm{mmol})$ and pyridine (py) (0.5 mL, $6.15 \mathrm{mmol}$ ) were dissolved in ${ }^{i}$ butanol $\left(\mathrm{HO}^{i} \mathrm{Bu}\right)$ $(15 \mathrm{~mL})$ and the solution was refluxed at $120{ }^{\circ} \mathrm{C}$ for 3 hours. The solution was filtered and then allowed to stand undisturbed at room temperature for nine days. Colourless platelike crystals suitable for single crystal $\mathrm{X}$-ray diffraction of $[\mathrm{pyH}]_{4}\left[\mathrm{Gd}_{4}{ }^{\mathrm{III}}\left(\mu_{3}-\mathrm{OH}\right)\left(\mathrm{O}_{3} \mathrm{P}^{t} \mathrm{Bu}\right)_{3}\left(\mathrm{HO}_{3} \mathrm{P}^{t} \mathrm{Bu}\right)\left(\mathrm{O}_{2} \mathrm{C}^{t} \mathrm{Bu}\right)_{2}\left(\mathrm{NO}_{3}\right)_{6}\right] \mathbf{1}$ were formed. Similar reactions with $\mathrm{Ln}^{\mathrm{III}}\left(\mathrm{NO}_{3}\right)_{3} \cdot n \mathrm{H}_{2} \mathrm{O}$, (where $\mathrm{Ln}^{\mathrm{III}}=\mathrm{Tb}$, Dy, Er and $\mathrm{Ho}$ ) gave analogous metal cages (Table 1).

\section{X-ray data collection and structure solution}

X-ray crystallographic measurements for compounds 1-5 were collected on an Agilent SUPERNOVA diffractometer with $\mathrm{MoK}_{\alpha}$ radiation $(\lambda=0.71073 \AA)$. In all cases the selected single crystals were mounted on a tip of a glass pin using Paraton-N oil and placed in a cold nitrogen flow. Structure solution and refinement was performed with the SHELXS-97 package, ${ }^{19 a}$ the structures were solved by direct method and completed by iterative cycles of $\Delta F$ synthesis and full-matrix least-squares refinement against $F^{2}$ using program Olex2. ${ }^{19 b}$ Crystal data and refinement parameters are given in Table 2. Complete hemispheres data were collected using $\phi$ and $\omega$ scans chosen to give a complete asymmetric unit. All atoms excluding hydro- gen were refined anisotropically. Hydrogen atoms were located on the basis of geometrical consideration and treated according to the riding model during refinement with isotropic displacement corresponding to the heavy atom they are linked to. Full crystallographic details can be found in CIF format: CCDC for 1-5, 1021470-1021474.

\section{Magnetic measurements}

Magnetic measurements were performed in temperature ranges 2-300 K, using a Quantum Design MPMS-XL7 SQUID magnetometer equipped with a $7 \mathrm{~T}$ magnet. The samples were grounded and placed in a gel capsule. A small amount of eicosane was used to avoid movement of the sample during the measurement. Diamagnetic corrections for the compounds were estimated using Pascal's constants, and the magnetic data were corrected for diamagnetic contribution of the gel capsule, the eicosane and the sample holder. Magnetic data were fitted using the program $\mathrm{PHI} .^{20}$

\section{Results and discussion}

\section{Synthetic description}

To date, just a few examples of lanthanide phosphonates cages have been reported due to the tendency of these systems to form polymeric materials. ${ }^{9}$ However we, and others, have recently proved that introducing of co-ligands along with aliphatic $\mathrm{R}$ groups on the phosphonate can render better solubility allowing their characterisation. This has led to families of $\left\{\operatorname{Ln}_{8} \mathrm{P}_{6}\right\}^{8 a}$ cages and $\left\{\operatorname{Ln}_{10} \mathrm{P}_{6}\right\}^{8 b}$ centred-rings. To illustrate how variation of other reaction conditions influence the product formed, herein we report the synthesis of five new lanthanide phosphonate clusters $\left\{\operatorname{Ln}_{4} \mathrm{P}_{4}\right\}$, using the same general procedure as used for synthesising $\left\{\operatorname{Ln}_{8} \mathrm{P}_{6}\right\}$, but replacing the base ${ }^{i} \mathrm{PrNH}_{2}$ with pyridine. Using an aromatic base produces a compound of lower nuclearity, containing four $\operatorname{Ln}(\mathrm{III})$ metal ions and four phosphonates. Three of the Ln(III) metal ions in the cluster form a $\mu_{3}-\mathrm{OH}$ centred triangle with the fourth Ln site capping this triangle.

\section{Crystal structures}

Compounds 1-5 crystallise in the monoclinic space group $C 2 / c$ and have the same molecular structures (Fig. 1); we describe

Table 1 Elemental analysis and yield (\%) for compounds 1-5

Elemental analysis: calculated (found)

\begin{tabular}{|c|c|c|c|c|c|c|c|}
\hline & \multirow[b]{2}{*}{ Formula } & \multirow[b]{2}{*}{ Yield $^{a}$} & & & & & \\
\hline & & & $\mathrm{C}$ & $\mathrm{H}$ & Ln & $P$ & $\mathrm{~N}$ \\
\hline 1 & {$[\mathrm{pyH}]_{4}\left[\mathrm{Gd}_{4}\left(\mu_{3}-\mathrm{OH}\right)\left(\mathrm{O}_{3} \mathrm{P}^{t} \mathrm{Bu}\right)_{3}\left(\mathrm{HO}_{3} \mathrm{P}^{t} \mathrm{Bu}\right)\left(\mathrm{O}_{2} \mathrm{C}^{t} \mathrm{Bu}\right)_{2}\left(\mathrm{NO}_{3}\right)_{6}\right]$} & $45 \%$ & $26.48(26.22)$ & $3.86(3.55)$ & $30.15(30.10)$ & $5.93(5.89)$ & $6.71(6.66)$ \\
\hline 2 & {$[\mathrm{pyH}]_{4}\left[\mathrm{~Tb}_{4}\left(\mu_{3}-\mathrm{OH}\right)\left(\mathrm{O}_{3} \mathrm{P}^{t} \mathrm{Bu}\right)_{3}\left(\mathrm{HO}_{3} \mathrm{P}^{t} \mathrm{Bu}\right)\left(\mathrm{O}_{2} \mathrm{C}^{t} \mathrm{Bu}\right)_{2}\left(\mathrm{NO}_{3}\right)_{6}\right]$} & $39 \%$ & $26.40(26.18)$ & $3.85(3.71)$ & $30.37(30.25)$ & $5.92(5.88)$ & $6.69(6.63)$ \\
\hline 3 & {$[\mathrm{pyH}]_{4}\left[\mathrm{Dy}_{4}\left(\mu_{3}-\mathrm{OH}\right)\left(\mathrm{O}_{3} \mathrm{P}^{t} \mathrm{Bu}\right)_{3}\left(\mathrm{HO}_{3} \mathrm{P}^{t} \mathrm{Bu}\right)\left(\mathrm{O}_{2} \mathrm{C}^{t} \mathrm{Bu}\right)_{2}\left(\mathrm{NO}_{3}\right)_{6}\right]$} & $30 \%$ & $26.22(26.11)$ & $3.82(3.79)$ & $30.84(30.77)$ & $5.88(5.73)$ & $6.67(6.61)$ \\
\hline 4 & {$[\mathrm{pyH}]_{4}\left[\mathrm{Ho}_{4}\left(\mu_{3}-\mathrm{OH}\right)\left(\mathrm{O}_{3} \mathrm{P}^{t} \mathrm{Bu}\right)_{3}\left(\mathrm{HO}_{3} \mathrm{P}^{t} \mathrm{Bu}\right)\left(\mathrm{O}_{2} \mathrm{C}^{t} \mathrm{Bu}\right)_{2}\left(\mathrm{NO}_{3}\right)_{6}\right]$} & $35 \%$ & $26.10(25.98)$ & $3.80(3.75)$ & $31.11(30.97)$ & $5.85(5.80)$ & $6.61(6.59)$ \\
\hline 5 & {$[\mathrm{pyH}]_{4}\left[\mathrm{Er}_{4}\left(\mu_{3}-\mathrm{OH}\right)\left(\mathrm{O}_{3} \mathrm{P}^{t} \mathrm{Bu}\right)_{3}\left(\mathrm{HO}_{3} \mathrm{P}^{t} \mathrm{Bu}\right)\left(\mathrm{O}_{2} \mathrm{C}^{t} \mathrm{Bu}\right)_{2}\left(\mathrm{NO}_{3}\right)_{6}\right]$} & $44 \%$ & $25.98(25.66)$ & $3.79(3.71)$ & $31.46(31.33)$ & $5.82(5.78)$ & $6.58(6.51)$ \\
\hline
\end{tabular}

${ }^{a}$ Calculated based on the lanthanide pivalate starting material. 
Table 2 Crystallographic information for clusters 1-5

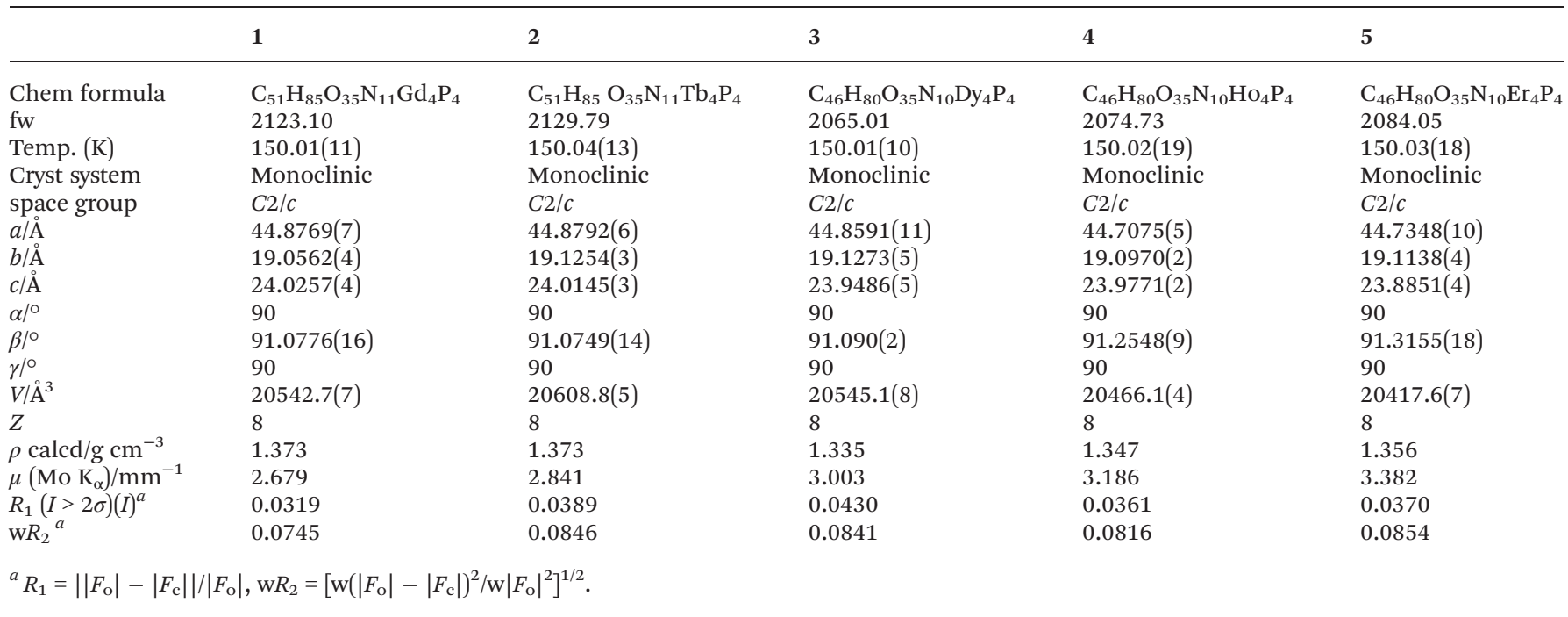
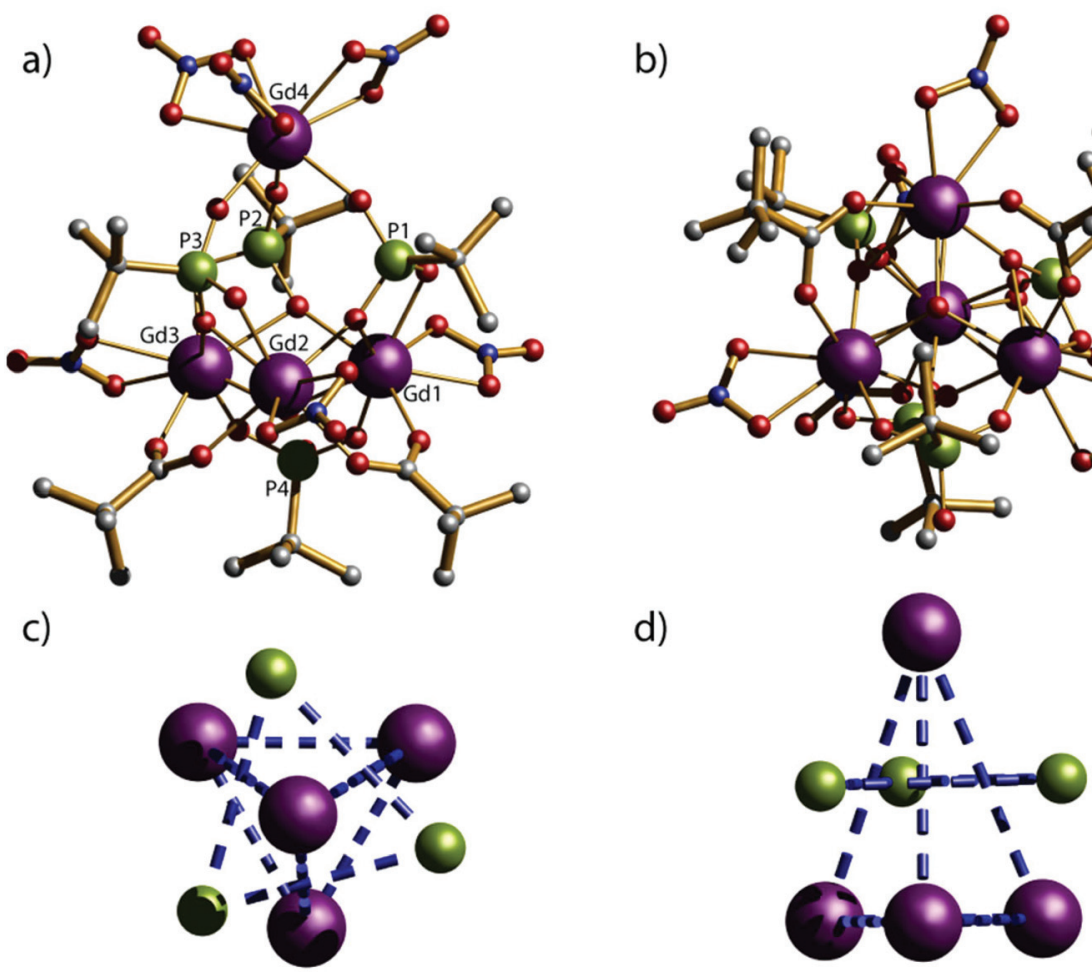

Fig. 1 (a) and (b) side and top view of Crystal structure of the $\left\{\mathrm{Gd}_{4} \mathrm{P}_{4}\right\}$ cluster. Scheme: Ln, purple; $\mathrm{P}$, green; O, red; C, grey; N, cyan; (H omitted for clarity); (c) and (d) top and side view of metal and phosphonate core of the crystal structure of $\left\{\mathrm{Gd}_{4} \mathrm{P}_{4}\right\}$ cluster.

the structure of $[\mathrm{pyH}]_{4}\left[\mathrm{Gd}_{4}{ }^{\mathrm{III}}\left(\mu_{3}-\mathrm{OH}\right)\left(\mathrm{O}_{3} \mathrm{P}^{t} \mathrm{Bu}\right)_{3}\left(\mathrm{HO}_{3} \mathrm{P}^{t} \mathrm{Bu}\right)\right.$ $\left.\left(\mathrm{O}_{2} \mathrm{C}^{t} \mathrm{Bu}\right)_{2}\left(\mathrm{NO}_{3}\right)_{6}\right] 1$ as representative. Overall the molecular cage contains four lanthanide metal ions, four phosphonates, six nitrates, one $\mu_{3}-\mathrm{OH}$ and two pivalates. The metallic core of 1 can be described as a triangular pyramid; the four Gd(III) ions (Gd1, Gd2, Gd3, and Gd4) lie on the vertexes of a triangular pyramid. The three phosphonate ligands sit above the triangular faces linking the base to the apex, and adopt the 3.111 bonding mode (Harris notation). ${ }^{21}$ The fourth phosphonate is located below the base of a triangular pyramid and bridges the (Gd1…Gd3) edge using the 2.11 bonding mode. There are six chelating nitrate ligands in the structure; one nitrate coordinates to each of the vertices in the triangular base and there are three nitrate ligands coordinated to the apex of the triangular pyramid (Gd4). Two of the Gd...Gd edges within the triangular base are bridged by 2.11 pivalates. 
The distances between $\mathrm{Gd} 1 \cdots \mathrm{Gd} 2, \mathrm{Gd} 2 \cdots \mathrm{Gd} 3$ and Gd1...Gd3 that are forming the edges of the base of the triangular pyramid are 3.8104(6), 3.8151(8) and 3.8642(6) $\AA$ respectively. The $\mu_{3}-\mathrm{OH}$ group is displaced about $0.8230(1) \AA$ out of the plane of the gadolinium metal ions. The Gd-O-Gd angles range from $108.34(11)$ to $109.19(10)^{\circ}$; these angles are consistent with a $\mu_{3}$-hydroxide and not with a bridging oxide. The distances between the plane of base (Gd1, Gd2 and Gd3) and the apex (Gd4) within the triangular pyramid are exactly $5.1150(1) \AA$.

Two different geometries are adopted by the $\mathrm{Gd}^{\mathrm{III}}$ ions in the cluster: whilst Gd2, Gd3 and Gd4 exhibit a biaugmented trigonal prism geometry $\left(C_{2 \mathrm{v}}\right)$ and a Continuous Shape Measure value (CShM) of 2.494, 2.573 and 2.434 respectively; Gd4 adopts a less regular coordination (muffin, Cs, with a CShM value of 2.345). ${ }^{22}$ There are no significant intermolecular interactions between clusters within the lattice.

\section{Magnetic description}

The magnetic properties of 1-5 were investigated by solid-state magnetic susceptibility (where $\chi_{\mathrm{M}}$ stands for molar magnetic susceptibility) measurements in the $2-300 \mathrm{~K}$ range in a 0.1 Tesla (T) DC field. The resulting data for complexes 1-5 are shown as $\chi_{\mathrm{M}} T$ versus $T$ plot in Fig. 2 and 3, respectively. In each case the room temperature value for $\chi_{\mathrm{M}} T$ is equivalent to that for four non-interacting metal ions of the appropriate type. For compounds 2-5 $\chi_{\mathrm{M}} T$ decreases steadily upon cooling down to ca. $90 \mathrm{~K}$ (Fig. 2), below which they drop at $2 \mathrm{~K}$, respectively. Such behaviour is typical for the individual metal ions concerned, and is probably due to depopulation of Stark levels within the individual metal sites. While magnetic exchange between the Ln sites in these compounds cannot be ruled out, there is certainly no evidence for such exchange from these measurements. Magnetisation $(M)$ versus applied magnetic field were performed at temperatures of 2 and $3 \mathrm{~K}$ in the field range of 0-7 T. For $1 \mathrm{M}$ saturates at $27.7 \mathrm{emu} \mathrm{K} \mathrm{mol}^{-1}$ at $7 \mathrm{~T}$ at $2 \mathrm{~K}$, as expected for four non-interacting $\mathrm{Gd}^{\mathrm{III}}$ metal ions with $S=7 / 2$ and $g_{\mathrm{Gd}}=1.99$ (Fig. 3). For compounds $2-5$, there is a gradual increase in $M v s$. $H$ curve with increasing field, which reach $20.8,22.7,23.7,21.5 \mu_{\mathrm{B}}$ at $7 \mathrm{~T}$ at $2 \mathrm{~K}$ without reaching saturation.

As $\mathrm{Gd}^{\mathrm{III}}$ is an isotropic metal ion this allowed us to simulate the magnetic data of complex 1. Structurally there is little difference between the Gd...Gd edges of the triangles (see above); however the Gd...Gd contacts between the apical Gd and those in the base are between 5.544(1)-5.604(1) A. Furthermore, any intermolecular interaction between would be rather small since the closest Gd...Gd intercluster distance is 9.8665(6) $\AA$. Based on this structure, we have fitted simultaneously $\chi_{\mathrm{M}} T(T)$ and $M(H)$, using the program $P H I,{ }^{20}$ using as a model
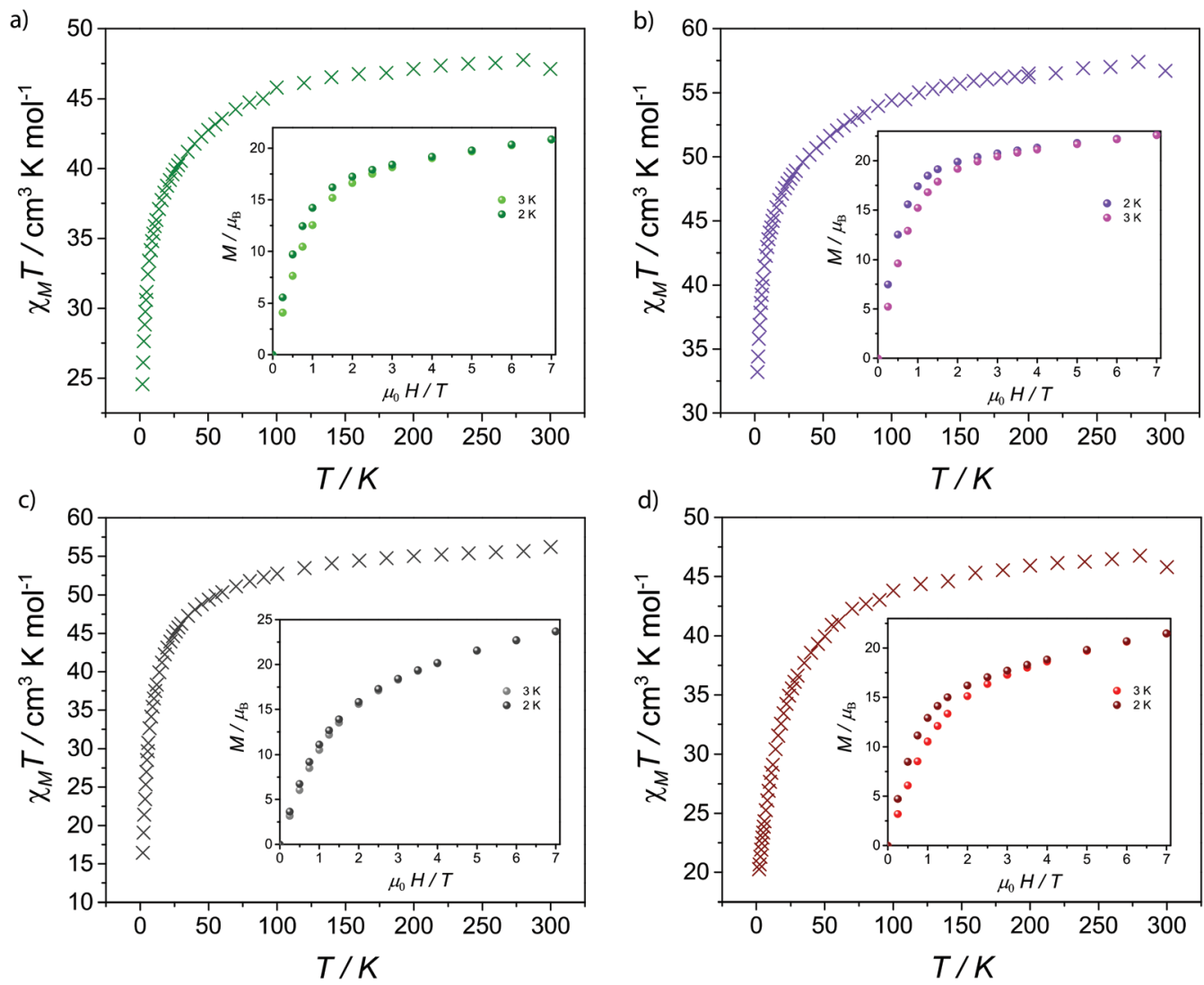

Fig. 2 Molar magnetic susceptibility $\left(\chi_{\mathrm{M}} T\right)$ vs. $T$ plot for 2-5 under $1 \mathrm{kG}$ dc field and molar magnetization $(M)$ as a function of applied magnetic field $(H)$ at 2 and $3 \mathrm{~K}$ (inset) for (a) 2, (b) 3, (c) 4 and (d) 5. 

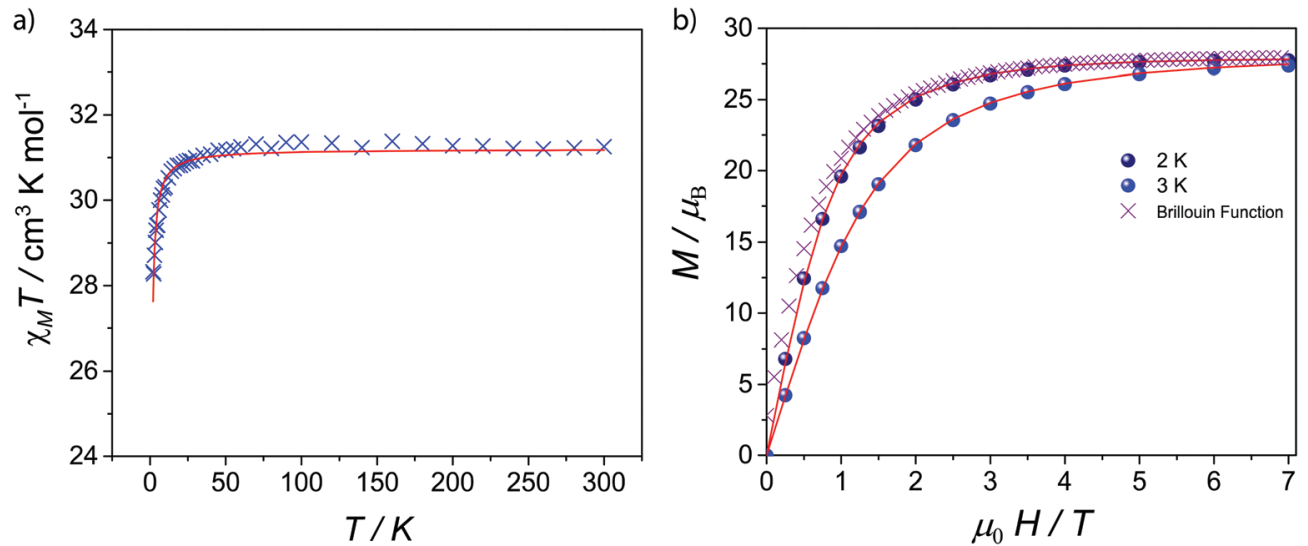

Fig. 3 (a) Molar magnetic susceptibility $\left(\chi_{\mathrm{M}} T\right)$ vs. $T$ and simulation plots for 1 under $1 \mathrm{kG}$ dc field; (b) Molar magnetization (M) as a function of applied magnetic field $(H)$ at 2 and $3 \mathrm{~K}$ for 1 .

an equilateral $\mathrm{Gd}_{3}$, with no exchange interaction to the fourth Gd, using the Hamiltonian (1).

$$
H=-2 J\left(\hat{S}_{1} \hat{S}_{2}+\hat{S}_{2} \hat{S}_{3}+\hat{S}_{1} \hat{S}_{3}\right)+g \mu_{B} H \sum_{i=1}^{4} \hat{S}_{i}
$$

where the first term is the isotropic exchange interaction between $\operatorname{Gd}(1) \cdots \operatorname{Gd}(2), \operatorname{Gd}(2) \cdots \operatorname{Gd}(3)$ and $\operatorname{Gd}(1) \cdots \operatorname{Gd}(3)$ and the second term is the Zeeman term of each Gd centre. This gives an antiferromagnetic exchange interaction $J=-0.01 \mathrm{~cm}^{-1}$ between the $\mathrm{Gd}$ ions, where $g=1.99$ (Fig. 3). Clearly with such a small interaction other models would also fit; we prefer this model as it has the minimum number of parameters and fits the crystallography (see above).
AC magnetic susceptibility measurements are a suitable method to judge whether a molecule exhibits a slow magnetisation relaxation rate, which is an essential property of a molecules that might be a single-molecule magnet (SMM). Such measurements were carried out between 10 and $1.8 \mathrm{~K}$ with and without applied DC field, however no out-of-phase component was obtained for any of the clusters.

\section{Discussion}

The core of compounds 1-5 is related to those found in $3 \mathrm{~d}-$ metal phosphonate cages (Fig. 4). ${ }^{12 a, b} \mathrm{An} \mathrm{Fe}($ (II) phosphonate a)

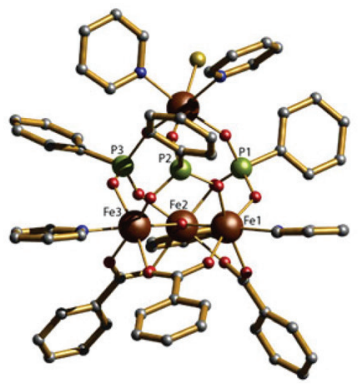

d)

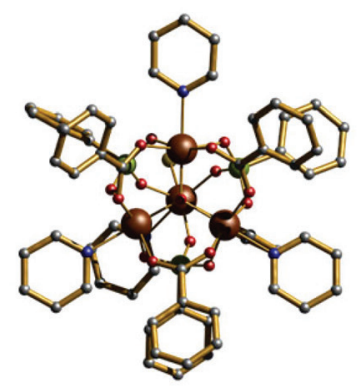

b)

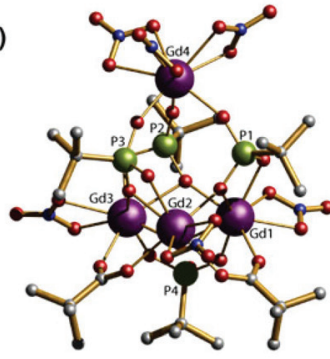

e)

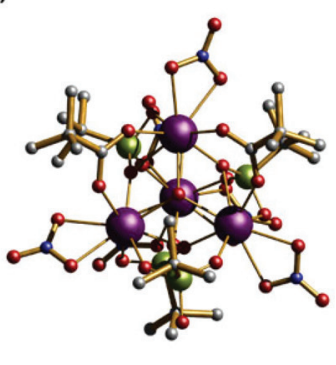

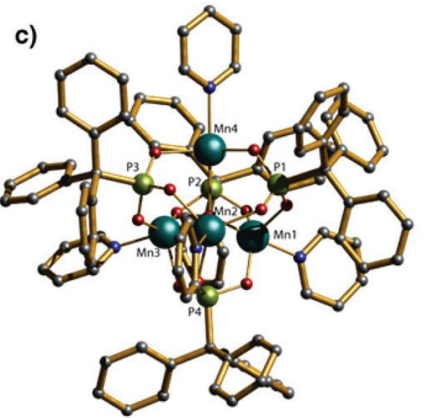

f)

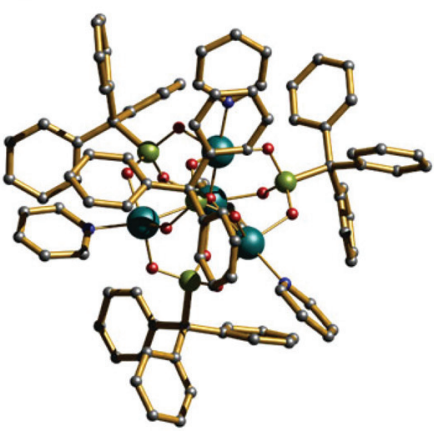

Fig. 4 (a) and (d) side and top view of crystal structure of the $\left\{\mathrm{Fe}_{4} \mathrm{P}_{4}\right\}$ cluster; (b) and (e) side and top view of Crystal structure of the $\left\{\mathrm{Ln}_{4} \mathrm{P}_{4}\right\}$ cluster; (c) and (f) side and top view of Crystal structure of the $\left\{\mathrm{Mn}_{4} \mathrm{P}_{4}\right\}$ cluster; Scheme: Ln, purple; Fe, brown; Mn, cyan; $\mathrm{P}$, green; O, red; C, grey; $\mathrm{N}$, cyan; (H omitted for clarity). 
cage $\left\{\mathrm{Fe}_{4} \mathrm{P}_{4}\right\}$ has been reported which contains a $\mu_{3}-\mathrm{O}$ centred triangle of $\mathrm{Fe}(\mathrm{III})$ sites capped by a fourth $\mathrm{Fe}^{\mathrm{III}}$ ion. The $\mu_{3}-\mathrm{O}$ $\mathrm{Fe}(\mathrm{III})$ triangle is clearly related to the oxo-centred $\left\{\mathrm{Fe}_{3}\right\}$ carboxylate triangle precursor. As in 1-5 three phosphonate units sit on the faces of the trigonal pyramid that link the base to the apex. All Fe(III) metal ion centres are six coordinated. The distance between the plane of base (Fe1, $\mathrm{Fe} 2$ and $\mathrm{Fe} 3$ ) and the apex (Fe4) is 4.25(1) $\AA$ while the $\mathrm{Fe}$...Fe distances within the triangular base of the tetrahedron are between 3.34 and $3.37 \AA$. A similar manganese phosphonate cage $\left\{\mathrm{Mn}_{4} \mathrm{P}_{4}\right\}$ involves the bulky tritylphosphonic acid (TPA) as ligand; this manganese cage is a mixed valent with two $\mathrm{Mn}^{\mathrm{II}}$ and two $\mathrm{Mn}^{\mathrm{III}}$ sites. In this compound all four faces of the triangle pyramid are occupied by TPA ligands and the oxo-centred Mn triangle is much more distorted with $\mathrm{Mn} \cdots \mathrm{Mn}$ distances within of 3.19 and $3.61 \AA$; the $\mathrm{Mn} \cdots \mathrm{Mn}$ distances to the apical Mn site remain longer at 3.88(1) $\AA$. In these $3 \mathrm{~d}$-cages, the phosphonates present 3.111 coordination mode and each metal ion centre is coordinated to a pyridine molecule to complete its coordination sphere. In the 4f-phosphonate compounds 1-5 reported here there is a $\mu_{3}-\mathrm{OH}$ centred triangle, not oxide centred, and the phosphonates show two diverse binding modes. There is no pyridine binding to $4 \mathrm{f}$ metals, with the coordination of the 4f-centres completed by chelating nitrates.

\section{Conclusions}

A new group of $4 \mathrm{f}$-phosphonate tetranuclear clusters have been synthesised from the reactions of a simple Ln(III) salt with $t$-butyl phosphonic acid. These products represent new additions to what is still a very small family of such molecular 4f-phosphonate species. We have previously reported that reaction of lanthanide nitrates with phosphonates in the presence of aliphatic base like isopropylamine produce a series of $\left\{\mathrm{Ln}_{8}\right\}$ clusters. ${ }^{20}$ Herein, our original goal of synthetic program was to explore whether same strategy with aromatic base could be used to assemble Ln(III) ions into large combinations with new structures and magnetic properties. It was observed that the reaction progress well in the presence of aromatic base, as the base promotes the reaction by deprotonation of the phosphonic acid ligand. So, in the present reaction system the identity of the cluster isolated is controlled by the nature of the base used, each single component of the reaction matrix has a strong effect on the final product, and hence on the magnetic behaviour. The magnetic susceptibility data for all complexes display dominant antiferromagnetic interactions. Hopefully further efforts in this area will lead to more magnetically interesting compounds.

\section{Acknowledgements}

KZ thanks the KRG-Scholarship program in "Human Capacity Development (HCDP)". EMP thanks the Panamanian agency SENACYT-IFARHU. REPW thanks the Royal Society for a
Wolfson Merit Award. We thank the EPSRC (UK) for funding for an X-ray diffractometer (grant number EP/K039547/1).

\section{References}

1 (a) S. K. Langley, M. Helliwell, R. Sessoli, P. Rosa, W. Wernsdorfer and R. E. P. Winpenny, Chem. Commun., 2005, 5029; (b) E. I. Tolis, L. P. Engelhardt, P. V. Mason, G. Rajaraman, K. Kindo, M. Luban, A. Matsuo, H. Nojiri, J. Raftery, C. Schroder, G. A. Timco, F. Tuna, W. Wernsdorfer and R. E. P. Winpenny, Chem. - Eur. J., 2006, 12, 8961; (c) S. K. Langley, M. Helliwell, R. Sessoli, S. J. Teat and R. E. P. Winpenny, Inorg. Chem., 2008, 47, 497; (d) J.-T. Li, Y.-S. Ma, S.-G. Li, D.-K. Cao, Y.-Z. Li, Y. Song and L.-M. Zheng, Dalton Trans., 2009, 5029; (e) M. Wang, C. Ma, H. Wen and C. Chen, Dalton Trans., 2009, 994.

2 (a) Y.-Z. Zheng, M. Evangelisti, F. Tuna and R. E. P. Winpenny, J. Am. Chem. Soc., 2012, 134, 1057; (b) V. Baskar, K. Gopal, M. Helliwell, F. Tuna, W. Wernsdorfer and R. E. P. Winpenny, Dalton Trans., 2010, 39, 4747.

3 (a) G. K. H. Shimizu, R. Vaidhyanathan and J. M. Taylor, Chem. Soc. Rev., 2009, 38, 1430; (b) A. Clearfeld, Curr. Opin. Solid State Mater. Sci., 1996, 1, 268.

4 (a) A. Clearfield, Curr. Opin. Solid State Mater. Sci., 2002, 6, 495; (b) E. M. Pineda, F. Tuna, R. G. Pritchard and A. C. Regan, Chem. Commun., 2013, 49, 3522; (c) M. Thompson, Chem. Mater., 1994, 6, 1168; (d) A. Subbiah, D. Pyle, A. Rowland, J. Huang, R. A. Narayanan, P. Thiyagarajan, J. Zon and A. Clearfield, J. Am. Chem. Soc., 2005, 127, 10826.

5 (a) V. Baskar, K. Gopal, M. Helliwell, F. Tuna, W. Wernsdorfer and R. E. P. Winpenny, Dalton Trans., 2010, 39, 4747; (b) Y.-Z. Zheng, M. Evangelisti and R. E. P. Winpenny, Angew. Chem., Int. Ed., 2011, 50, 3692; (c) Y.-Z. Zheng, E. M. Pineda, M. Helliwell, M. Evangelisti and R. E. P. Winpenny, Chem. - Eur. J., 2012, 18, 4161; (d) E. M. Pineda, F. Tuna, Y.-Z. Zheng, S. J. Teat, R. E. P. Winpenny, J. Schnack and E. J. L. McInnes, Inorg. Chem., 2014, 53, 3032; (e) M. I. Khan and J. Zubieta, Prog. Inorg. Chem., 1995, 43, 1; $(f)$ V. Chandrasekhar and S. Kingsley, Angew. Chem., Int. Ed., 2000, 39, 2320.

6 (a) J.-G. Mao, Chem. Rev., 2007, 251, 1493; (b) S.-M. Ying and J.-G. Mao, Cryst. Growth Des., 2006, 6, 964; (c) S.-F. Tang, J.-L. Song, X.-L. Li and J.-G. Mao, Cryst. Growth Des., 2007, 7, 360; (d) Y.-Q. Guo, S.-F. Tang, B.-P. Yang and J.-G. Mao, J. Solid State Chem., 2008, 181, 2713.

7 G. Cao, V. M. Lynch, J. S. Swinnea and T. E. Mallouk, Inorg. Chem., 1990, 29, 2112.

8 (a) K. H. Zangana, E. M. Pineda, J. Schnack and R. E. P. Winpenny, Dalton Trans., 2013, 42, 14045; (b) K. H. Zangana, E. M. Pineda, E. J. L. McInnes, 
J. Schnack and R. E. P. Winpenny, Chem. Commun., 2014, 50, 1438.

9 (a) J.-G. Mao, Coord. Chem. Rev., 2007, 251, 1493; (b) S.-M. Ying and J.-G. Mao, Cryst. Growth Des., 2006, 6, 964; (c) S.-F. Tang, J.-L. Song, X.-L. Li and J.-G. Mao, Cryst. Growth Des., 2007, 7, 360; (d) Y.-Q. Guo, S.-F. Tang, B.-P. Yang and J.-G. Mao, J. Solid State Chem., 2008, 181, 2713.

10 V. Chandrasekhar and S. Kingsley, Angew. Chem., Int. Ed., 2000, 39, 2320.

11 (a) S. Maheswaran, G. Chastanet, S. J. Teat, T. Mallah, R. Sessoli, W. Wernsdorfer and R. E. P. Winpenny, Angew. Chem., Int. Ed., 2005, 44, 5044; (b) M. Shanmugam, G. Chastanet, T. Mallah, R. Sessoli, S. J. Teat, G. A. Timco and R. E. P. Winpenny, Chem. - Eur. J., 2006, 12, 8777.

12 (a) E. I. Tolis, M. Helliwell, S. Langley, J. Raftery and R. E. P. Winpenny, Angew. Chem., Int. Ed., 2003, 42, 3804; (b) S. Konar and A. Clearfield, Inorg. Chem., 2008, 47, 3492.

13 (a) S. Langley, M. Helliwell, R. Sessoli, S. J. Teat and R. E. P. Winpenny, Inorg. Chem., 2008, 47, 497; (b) S. Langley, M. Helliwell, R. Sessoli, S. J. Teat and R. E. P. Winpenny, Dalton Trans., 2009, 3102; (c) S. K. Langley, M. Helliwell, S. J. Teat and R. E. P. Winpenny, Dalton Trans., 2012, 41, 12807.

14 (a) B. A. Breeze, M. Shanmugam, F. Tuna and R. E. P. Winpenny, Chem. Commun., 2007, 5185; (b) S. K. Langley, M. Helliwell, S. J. Teat and R. E. P. Winpenny, Inorg. Chem., 2014, 53, 1128.

15 (a) V. Chandrasekhar and S. Kingsley, Angew. Chem., Int. Ed., 2000, 39, 6175; (b) V. Chandrasekhar, L. Nagarajan, K. Gopal, V. Baskar and P. Kögerler, Dalton Trans., 2005, 3143; (c) V. Chandrasekhar, L. Nagarajan, R. Clérac, S. Ghosh, T. Senapati and S. Verma, Inorg. Chem., 2008, 47, 5347.

16 (a) S. Khanra, M. Kloth, H. Mansaray, C. A. Muryn, F. Tuna, E. C. Sañudo, M. Helliwell, E. J. L. McInnes and R. E. P. Winpenny, Angew. Chem., Int. Ed., 2007, 46, 5568; (b) S. Khanra, L. Batchelor, M. Helliwell, F. Tuna, E. J. L. McInnes and R. E. P. Winpenny, J. Mol. Struct.,
2008, 890, 157; (c) S. Khanra, R. Shaw, M. Helliwell, F. Tuna, C. A. Muryn, E. J. L. McInnes and R. E. P. Winpenny, Materials, 2010, 3, 232.

17 (a) K. Brechin, R. A. Coxall, A. Parkin, S. Parsons, P. A. Tasker and R. E. P. Winpenny, Angew. Chem., Int. Ed., 2001, 40, 2700; (b) E. I. Tolis, M. Helliwell, S. Langley, J. Raftery and R. E. P. Winpenny, Angew. Chem., Int. Ed., 2003, 42, 3804; (c) E. I. Tolis, L. P. Engelhardt, P. V. Mason, G. Rajaraman, K. Kindo, M. Luban, A. Matsuo, H. Nojiri, J. Raftery, C. Schroder, G. A. Timco, F. Tuna, W. Wernsdorfer and R. E. P. Winpenny, Chem. - Eur. J., 2006, 12, 8961; (d) M. Maheswaran, G. Chastanet, S. J. Teat, T. Mallah, R. Sessoli, W. Wernsdorfer and R. E. P. Winpenny, Angew. Chem., Int. Ed., 2005, 44, 5044; (e) M. Shanmugam, G. Chastanet, T. Mallah, R. Sessoli, S. J. Teat, G. A. Timco and R. E. P. Winpenny, Chem. - Eur. J., 2006, 12, 8777.

18 (a) I. G. Fomina, M. A. Kiskin, A. G. Martynov, G. G. Aleksandrov, Z. V. Dobrokhotova, Y. G. Gorbunova, Y. G. Shvedenkov, A. Y. Tsivadze and V. M. Novotortsev, Zh. Neorg. Khim., 2004, 49, 1463; (b) T. A. Zoan, N. P. Kuzmina, S. N. Frolovskaya, A. N. Rykov, N. D. Mitrofanova, S. I. Troyanov, S. I. Pisarevsky, A. P. Martynenko and L. I. Korenev, J. Alloys Compd., 1995, 225, 396.

19 (a) G. M. Sheldrick, Acta Crystallogr., 2008, A64, 112; (b) O. V. Dolomanov, L. J. Bourthis, R. L. Gildea, J. A. K. Howard and H. Puschmann, J. Appl. Crystallogr., 2009, 42, 339.

20 N. F. Chilton, R. P. Anderson, L. D. Turner, A. Soncini and K. S. Murray, J. Comput. Chem., 2013, 34, 1164.

21 Harris notation describes the binding mode as $[X . Y 1 Y 2 \ldots$ Yn] where $X$ is the overall number of metal bond by the whole ligand, and each value of $Y$ refers to the number of metal atoms attached to the different donor atoms. See ESI $\dagger$ and R. A. Coxall, S. G. Harris, D. K. Henderson, S. Parsons, P. A. Tasker and R. E. P. Winpenny, Dalton Trans., 2000, 14, 2349.

22 (a) S. Alvarez, Dalton Trans., 2005, 2209; (b) S. Alvarez, P. Alemany, D. Casanova, J. Cirera, M. Llunell and D. Avnir, Coord. Chem. Rev., 2005, 249, 1693. 